\title{
Influence of Spatial Planning on Socio-Cultural Inclusion in Urban Parks of Abu Dhabi
}

\author{
Asif Abdulrahiman KARAPPAMVEETIL, Sorbonne University Abu Dhabi, United Arab Emirates
}

\begin{abstract}
Today, cities have developed strategies to ensure social interaction in urban spaces along with extensive research on general requirements of the same. However, a research gap exists in the needs, wants and expectations of multiple users within a society. Also, urban planners often seem to overlook the influence of spatial layout on socio-cultural perspectives of people in multicultural countries like the United Arab Emirates. The research thus focuses on the concept of culturally diverse social inclusion, and the influence of spatial layouts within urban open spaces. With inferences from the literature review and case studies, parameters found were used to analyse two selected urban parks in Abu Dhabi: Reem Central Park (neighbourhood park) and Khalidiya Park (city park). Methods like photography were used in understanding spatial activities from different focal lengths, along with map layering, drawing and sketching to understand spatial layout in relation with social inclusion. To ensure a socio-cultural future in multi-cultural cities like Abu Dhabi, certain policies and guidelines are formulated through this research. The research also shows the use of hypothetical maps of people's aspirations, based on the understanding of people's cultural backgrounds and park practices, to understand how people would ideally use these spaces, and concludes by recommending an extensive spatial approach in building spaces which will contribute to better living conditions for the migrants in the city.
\end{abstract}

\section{Keywords}

Activity, Human Behaviour, Inter-Culturalism, Social Inclusion, Spatial Layout, Urban Spaces

\section{Introduction}

\subsection{Research Background}

Considering the growth of the cities in a global scale along with migration, are countries really catering to its immigrant majority by making public spaces more accessible to all cultural groups? The concept of 'transnational urbanism' results in situations where an immigrant is 'in-between' everyday practices that might be opposing; he/she must comply with two or more sets of rules and norms and ultimately must be able to function in two, probably completely different, realities. This 'in-betweenness' and the ways that they have to negotiate their position and their everyday experience are directly linked to the ways that they use urban public space (Trikalinou, 2015). Therefore, an in-depth exploration of the lives of migrants is essential to understand their standards of living and social opportunities in a society through which both these people are able to establish their identity in the new place and to understand how places influences their behavioral decisions.

\subsection{Research Framework}

As a first step towards the research, the existing gap was identified. It was found that there are studies on requirements of public spaces in general, but there is a gap in research to what are the needs, wants and 
expectations of the other sectors of the society. Case studies around the world indicate the practices of people from diverse cultural backgrounds in urban open spaces like parks but the influence of spatial layout on these cultural practices have been often overlooked. The idea of inclusive urban planning and design is often based on 'the assumption that the society is made of a homogeneous majority and a number of marginal minorities' needs revision (Madanipour, 2007). Moreover, it was found that there is a lack of study in this domain among the middle eastern countries due to lower no. of institutions.

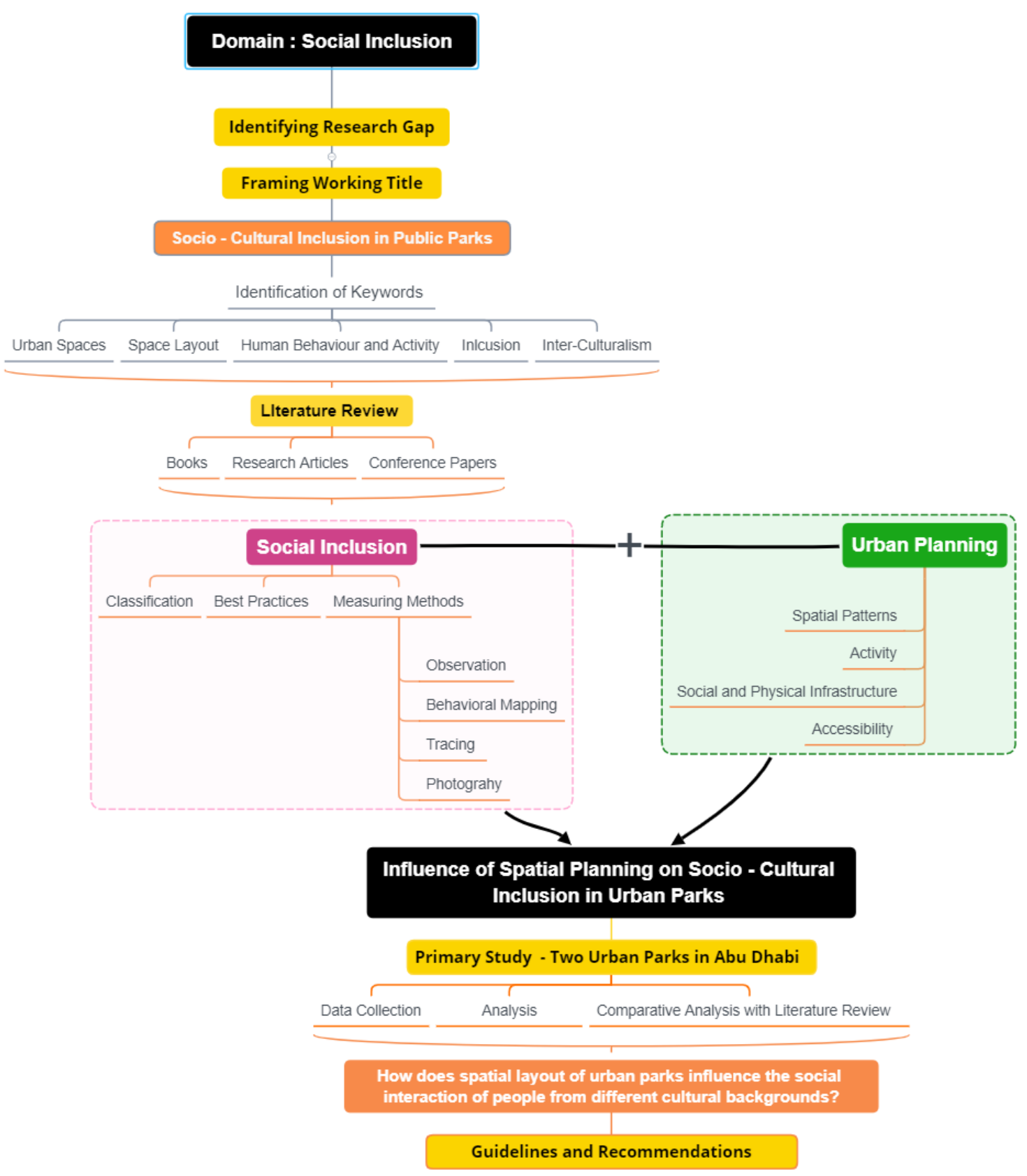

Figure 1 Research Framework

Thereby, it became necessary to explore the requirements in urban spaces with a different perspective and complement the large amount of research that already exists, especially in a country like Abu Dhabi where multi-culturalism exists. The research question was thus formulated as follows:

How does spatial layout of urban spaces influence the social interaction of people from different cultural backgrounds? 


\section{Literature Review}

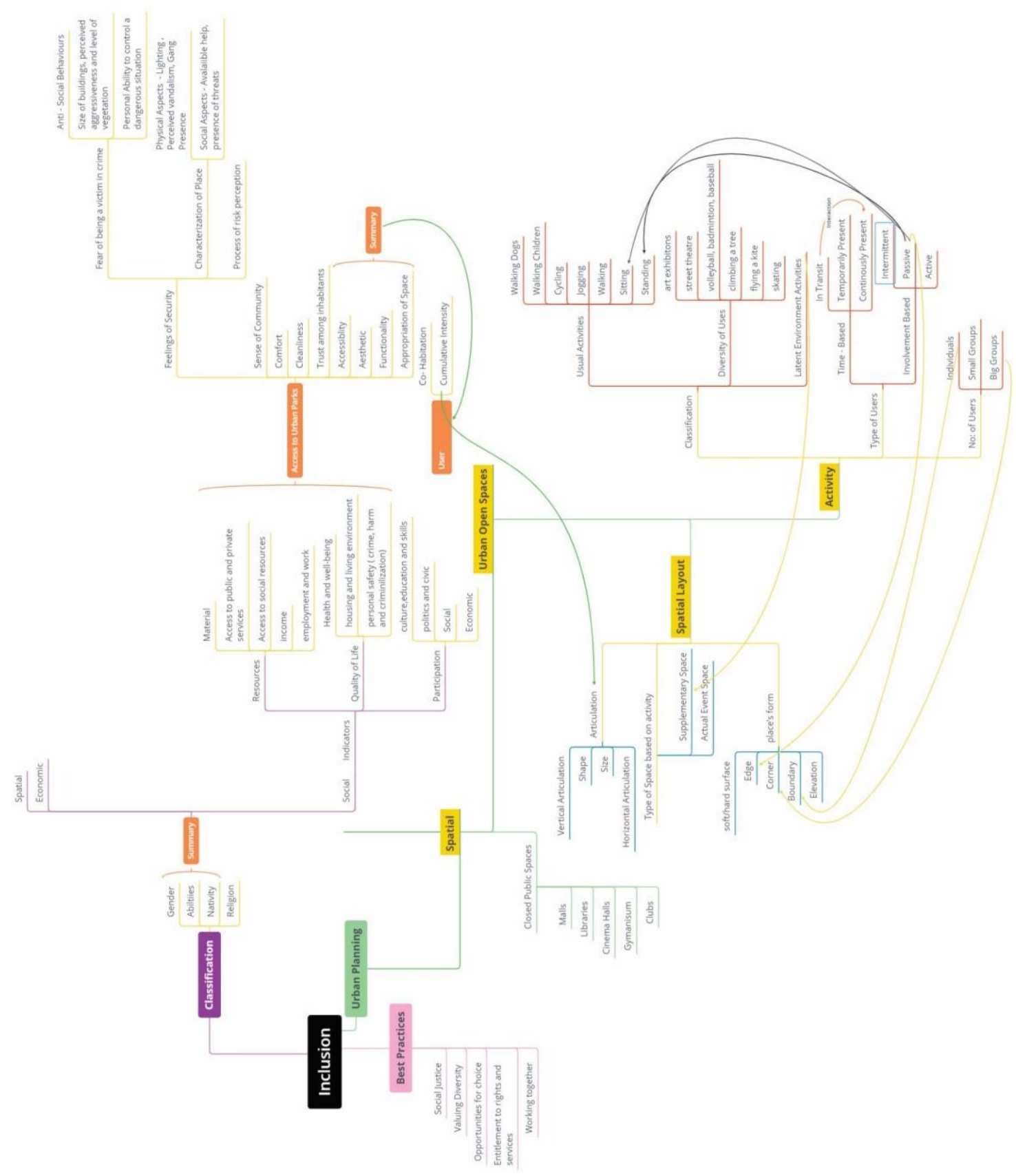

Figure 2 Conclusion of parameters from literature review, shown as a mind map in the beginning

\subsection{Context and 'publicness'}

The definition of public space varies to a huge extent in the modern context. So far, several authors have defined "public space" by emphasizing different aspects of the same. Since, my approach focuses on how migrants and various nationalities utilize public open spaces in Abu Dhabi, public spaces as defined by Carr are seen as the "stage upon which the drama of communal life unfolds" (Carr et al., 1993). 
According to Jacobs and Appleyard (Jacobs and Appleyard, 1987), good public spaces have the following characteristics such as livability, identity and control, access to opportunity, imagination, joy, authenticity and meaning, open communities and public life, and, self-reliance.

The ability to carry out activities as the user wishes, to enjoy the space, to manipulate the space feeling no control, are other factors that influence the publicness of an urban space (Low, 2002). However, these rights are limited by policies and surveillance in most of the public spaces across the world (Low, 1996). The character of publicness of parks hence depends on the degree of control of the space and how it is manipulated. This can often lead to form of contestation or struggles over space (Mitchell, 2003). These are influenced by the patterns of social inclusion / exclusion practices in a city.

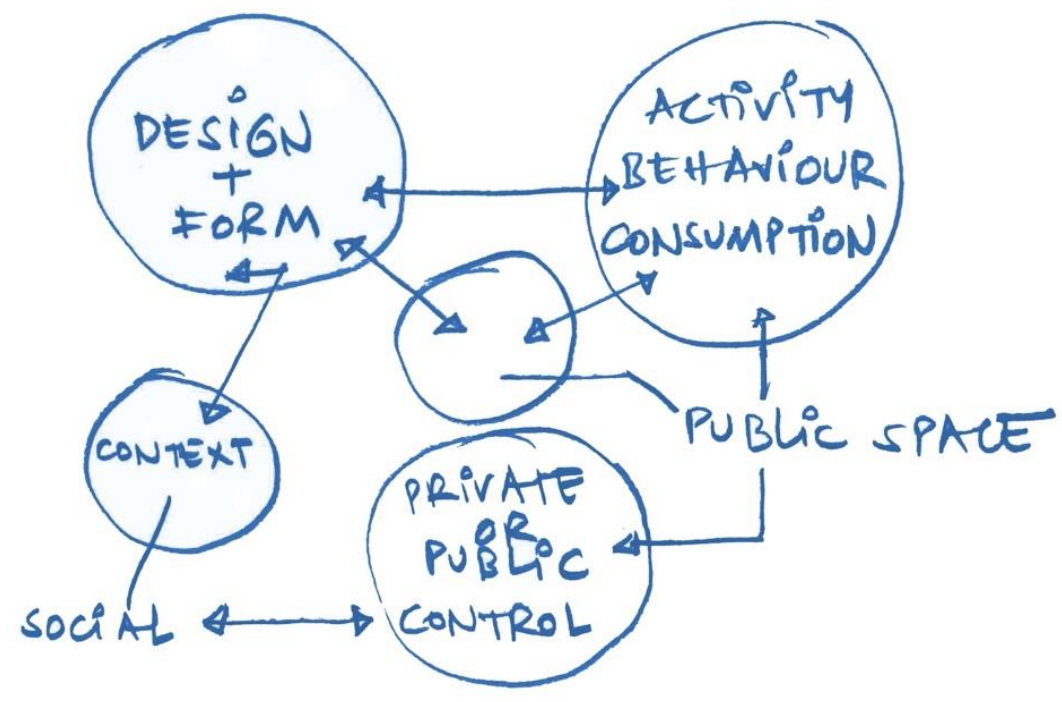

Figure 3 Production of Space

\subsection{Factors affecting Social Inclusion}

Social inclusion is defined as the process of improving the terms of participation in society, particularly for people who are disadvantaged, through enhancing opportunities, access to resources, voice and respect for rights (United Nations Department of Economic and Social Affairs, 2016). Proximity to urban open spaces i.e.; distance to these spaces is a key factor that affects regular use by people. According to (Kloek et al., 2013), people may use urban open spaces based on the following three aspects:

- Emotional barriers - sense of safety and feeling of discrimination

- Practical barriers - language, competency, time, budget, access to transport

- Socio - cultural values and norms

\subsection{Migration and Culture}

For the immigrants, as they shift to a new country, they experience a new life in the host country compared to what they did in their native country. New urban open spaces could foster feelings of nostalgia in them. Hence, in multi -cultural cities, new attachments and inclusiveness develops when one is able to present himself and when others are visible in these everyday urban open spaces creating familiarization (Rishbeth and Powell, 2013). Therefore, place attachment is also an important factor affecting social inclusion.

The difference in experiences for migrants is also a result of the differences in culture in a city. It is their constant socio -cultural struggle to shape their conditions that reflects in the shaping of cities linked to inter-culturalism. Inter-culturalism is the concept of not just accepting and maintaining the difference 
between culture but also incorporating minority groups cross-cultural activities, dialogues and organizations: in essence, all spheres of public life (Sandercock and Lyssiotis, 2003). The everyday intercultural encounter would foster more mutual growth creating happy societies.

Urban public open spaces create possibilities for intercultural learning (Amin, 2002). But they also are spaces that provide opportunities for less intensity intermingling, though it creates a feeling of togetherness. Urban open spaces like Parks are often associated with leisure activities or relaxation, leading to minimal social interaction. Urban parks are often designed to act as micro-public spaces where, through intimate proximity, healthy encounters and negotiations can take place.

Migrants bring with them into the park many of the perceptual habits, cultural 'ways', and expectations about nature that were formed in their homelands (Byrne and Goodall, 2013). African - Americans preferred shaped and organized built environment with open spaces such as ball fields and paved trails, than wilderness setting and were less likely to recreate compared to the Whites and the Dutch (Johnson et al., 1997). In fact, a study in Chicago's Lincoln Park revealed that the African - Americans care more about the service and maintenance quality compared to Asians who prefer trees and vegetation (Gobster, 2002).

A research in regional parks of Chicago reveals that Hispanic groups are engaged in immobile/ stationary activities whereas Whites and Black Activity groups engage in mobile activities (Hutchison, 1994). The African - Americans are more involved in fitness activities and socializing, but Hispanics and Asians have more interests in picnicking than them. In eastern United States, Koreans, African-Americans, and Hispanics were more likely than Whites, Chinese and Japanese to participate in food related activities in park (Sasidharan, 2000). The Whites enjoy the aesthetic qualities and use the park mostly for jogging and walking (Özgüner, 2011). They also carry out activities like bicycling, dog walking, bring children and enjoy peace and quiet (Greenhalgh et al., 1995). But unlike the Whites, the Arabs and Turkish express their 'fear of dogs' in UK, as keeping a dog as a pet in not a common tradition for them (Rishbeth, 2004).

According to a study conducted in two parks close to the city centre in Al Ain, U.A.E. by Khaled Alawadi, a very low percentage of Emiratis were seen in parks during weekdays. In Al Jahili Park, during the mornings, Westerners dominated the park and South Asians and Arabs in the evening. Arab Females were engaged in reciting Quran in groups during different times of the day and Arab Families preferred highly vegetated spaces for privacy unlike South Asian Bachelors who preferred open spaces and areas closer to the road (Alawadi, 2018). Whereas in Al Selimi Park, except for a few South - Asian and Filipino workers or salespeople who would come to rest and spend their lunch breaks, the park is empty during the mornings. However, on Friday evenings, Arabs dominated the park under canopied trees relaxing. South Asians were seen to be playing card games (Alawadi, 2018).

In Sydney's urban park, an average picnic would be attended by 1-50 people in Arab families mostly to mark occasions such as birthdays. They create a micro-environment of their own through activities like the Hookah. Also, they are seen kneeling to pray at different times as per their religion facing towards the Kaaba in Mecca and breaking meals during Ramadan (Byrne and Goodall, 2013). It is the looseness of the park that allows them to transform the space as they wish which could not have been possible in other public spaces.

Asian groups have high values of open spaces in UK, because it's part of their culture to have family gatherings back at their native countries like India (Burgess, Harrison and Limb, 1988). In the US, based on a study in a national park by Setha Low, it was observed that Latino groups picnicked in the 'back beach' area singing and dancing creating a nostalgia of their home (Setha Low, Dana Taplin, 2005.) In a national park in Sydney, Vietnamese immigrants mention about how the presence of rivers evoked memories of Vietnam. Also, some Vietnamese Buddhists established 'forest monasteries' like their homeland in Sydney's parks to meditate. For the Arabs, water is related to paradise too. (Byrne and Goodall, 2013). 
In Alawadi's study, it was found that though Al Ain has a higher number of Emiratis, the females hesitate to come to parks due to lack of perceived safety. Compared to women from western countries, new immigrant women especially from Asian countries and Turkey engage less in urban parks as they are oriented to long hours of household work, language barriers, which eventually leads to exclusion due to accessibility issues (Eyler et al., 2002). Also, women prefer to visit open spaces in groups fearing safety.

Either immigrants explore new ways to express their culture in new urban open spaces, or refuse to access spaces due to discrimination, or try and match with existing culture, or use both.

\subsection{AD Vision 2030}

The Abu Dhabi Vision Plan 2030 clearly identifies key qualities needed for public spaces such as safety, shopping, entertainment, and also highlights missing community facilities.

As Parks, Streetscapes, Waterfronts and Public Places are evaluated, de-signed and developed; typologies, facilities and access are considered in the context of these standards. These values should be continually reassessed as population changes to ensure the public realm is developed optimally, but the research suggests a need to design for social health and to address the existing gaps in practice.

\section{Research Methodology}

- Visual observations as participatory covert observations.

- Behavioral maps at hourly intervals by noting group activities by time and place to see how different activities and categories of individuals are scattered over time and space (people pass through, stop, specific usage), contestation of space and peak usage.

- Mapping the pathway of each user over a 10-minute observation period - to find time-geography paths and to analyze how they are segregated by use characteristics. P

- Photography to understand contestation of space, social and spatial boundaries and identify spots based on ethnicity, gender, age and class.

The schedule for observations were as follows:

\begin{tabular}{|l|l|l|}
\hline Day & Timeslot & Timeslot \\
\hline Weekday & $08: 00-10: 00$ & $17: 00-19: 00$ \\
\hline Friday & $10: 00-12: 00$ & $19: 00-21: 00$ \\
\hline Saturday & $08: 00-10: 00$ & $17: 00-19: 00$ \\
\hline
\end{tabular}

\section{Primary Study and Analysis}

\subsection{Reem Central Park, Reem Island, Abu Dhabi}

Located 600 meters off the north eastern coast of Abu Dhabi, Al Reem Island is one of the first free trade zones in the capital. It is a mixed purpose community with both residential, retail and commercial units. Residents who consider moving to Al Reem Island expect to indulge modern luxuries and amenities from all the properties. 


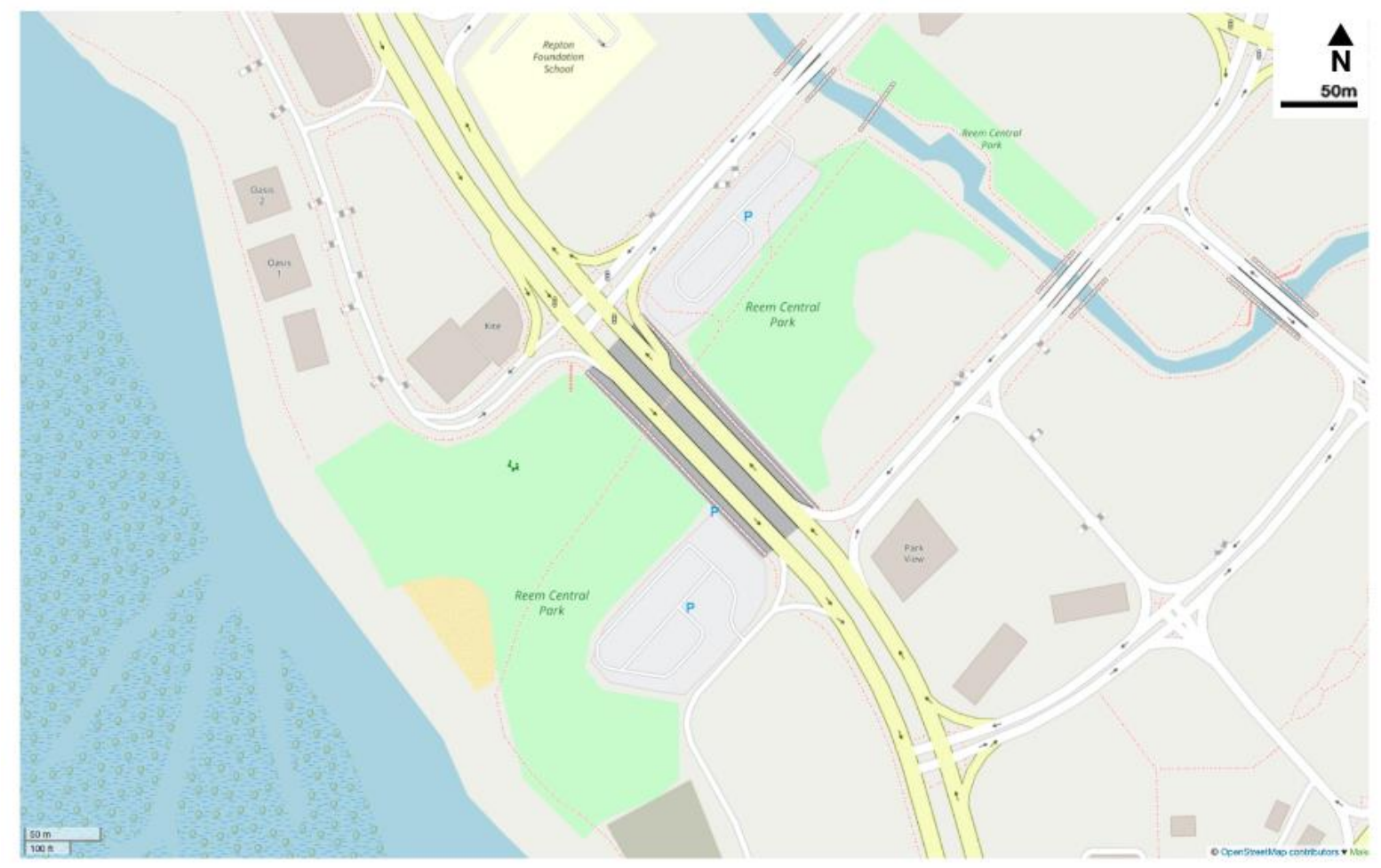

Figure 4 Reem Central Park

The central element within Reem Central Park is the skate park. It is located under a flyover, which acts as a bridge between two sides of the road. While this vastly improves accessibility, it acts as a transition between two edges within the district. This directly translates into better life between buildings. Social interaction between people is dramatically improved intuitively, as people are psychologically removing invisible barriers through efficient urban design. The other benefit being in a planning scale, this can be adopted into a typology to reuse these voids beneath flyovers.

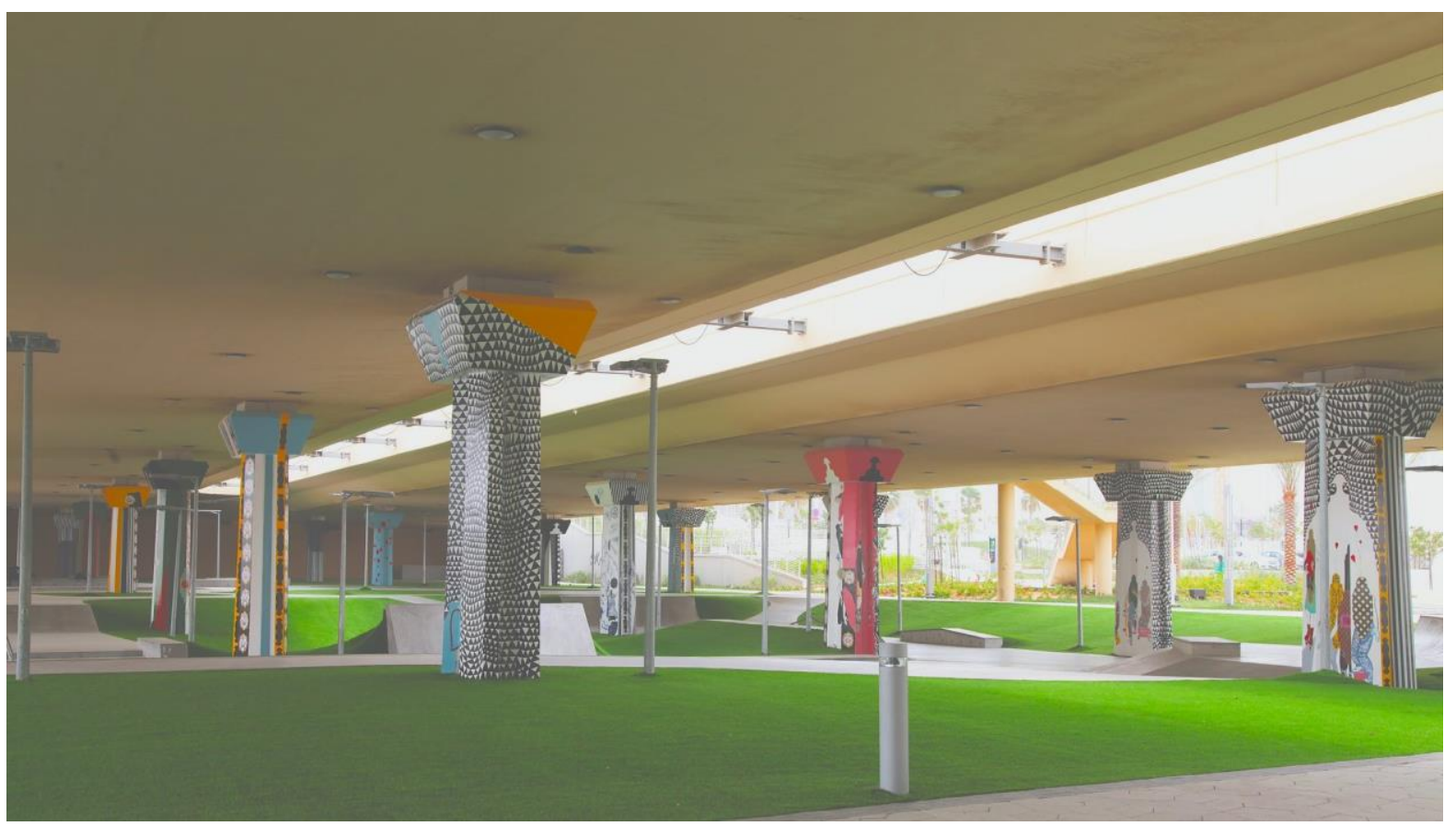

Figure 5 Skate Park under the flyover, Source: (Mena,2019) 
Transparent elements within public space encourage curiosity and the willingness to move and explore, especially in the case of children. Even though humans generally get familiar with the layout over time, children always want to discover more, day after day. When it comes to adults, during sunny days we can see a trend where they converge towards the flyover. Finding a shaded area is a common goal among adults especially during the day, and the space under the flyover helps people find and create a mutual space reducing the boundaries between them. This example is used to demonstrate the flyover as a temporarily present space for children and continuously present space for adults. The nature of the space makes it a passive space for adults and an active space for children. Another important aspect here is the layout itself. The space under the flyover is perpendicular to access path leading to it. This encourages cross articulation which are advantageous to groups both big and small. The space consists of both hard and soft surfaces enabling individuality.

Although the cycling activity has its own path, it is unknowingly creating barriers for the people in the background as well. People who are stationery are generally more perceptive of their surroundings than people who are walking or cycling. These stationery people are taking part in activities passively, and open spaces between activity edges encourage interaction. Edges are a very important part in public spaces as not only do they define the place's form but also spatial occupation for the users.

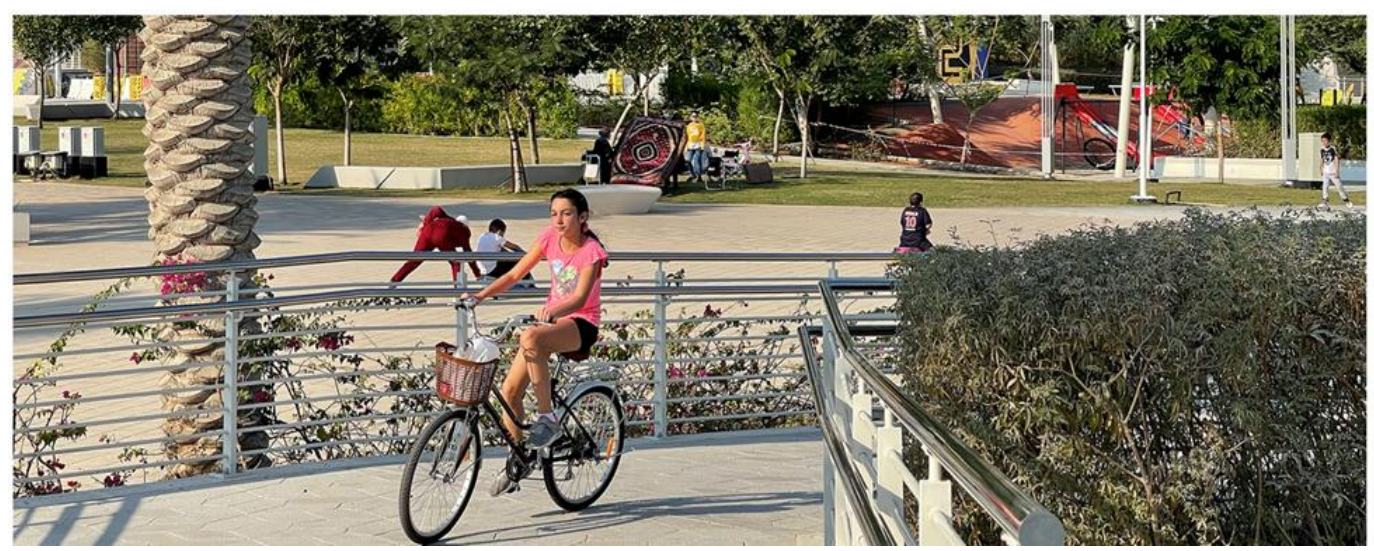

Figure 6 Defined Cycling Path

Hardscape and softscape elements also contribute in a similar manner and in many cases dictate the number of users and size of the groups. Children although active during the evening, seem tired and sleepy as compared to during the day. Adults on the other hand want to mostly unwind after a long day at work, and seem very relaxed during the evening. The beach is also an attraction here in the park, as it gives the people an option to move and watch the sunset. People are drawn to it, regardless of ethnic profile. During sunset, the borders between people are significantly reduced.

There are a few unfavorable conditions as well. These cannot be observed from up close, but when you take a step back to zoom out and observe we can notice the many hidden anomalies. The Park is located within a neighborhood that caters to a social premium, as compared to other parks located within the city, which cater to different types of people, from various ethnicity to various income levels. Although accessible by everyone, some groups exhibit the lack of will to explore and be dynamic. Observing them for over an hour, they seem to prefer sitting against a signage board, talking to each other. It was found that they are observing other people as well. Similar instances can be seen regularly, where people feel they don't quite fit in, and prefer to stay away from the others in the park. In the eyes of others, this behavior can be seen as undesirable. Observation from different focal lengths has helped in understanding the scale of the park, and the overall usage. The closer you are in Reem Park, the fuller of life it appears. Although advantageous to have a big park, occupancy is rarely more than half of its capacity, despite the larger catchment area. The case is true for all times during the day, in any direction of observation. 


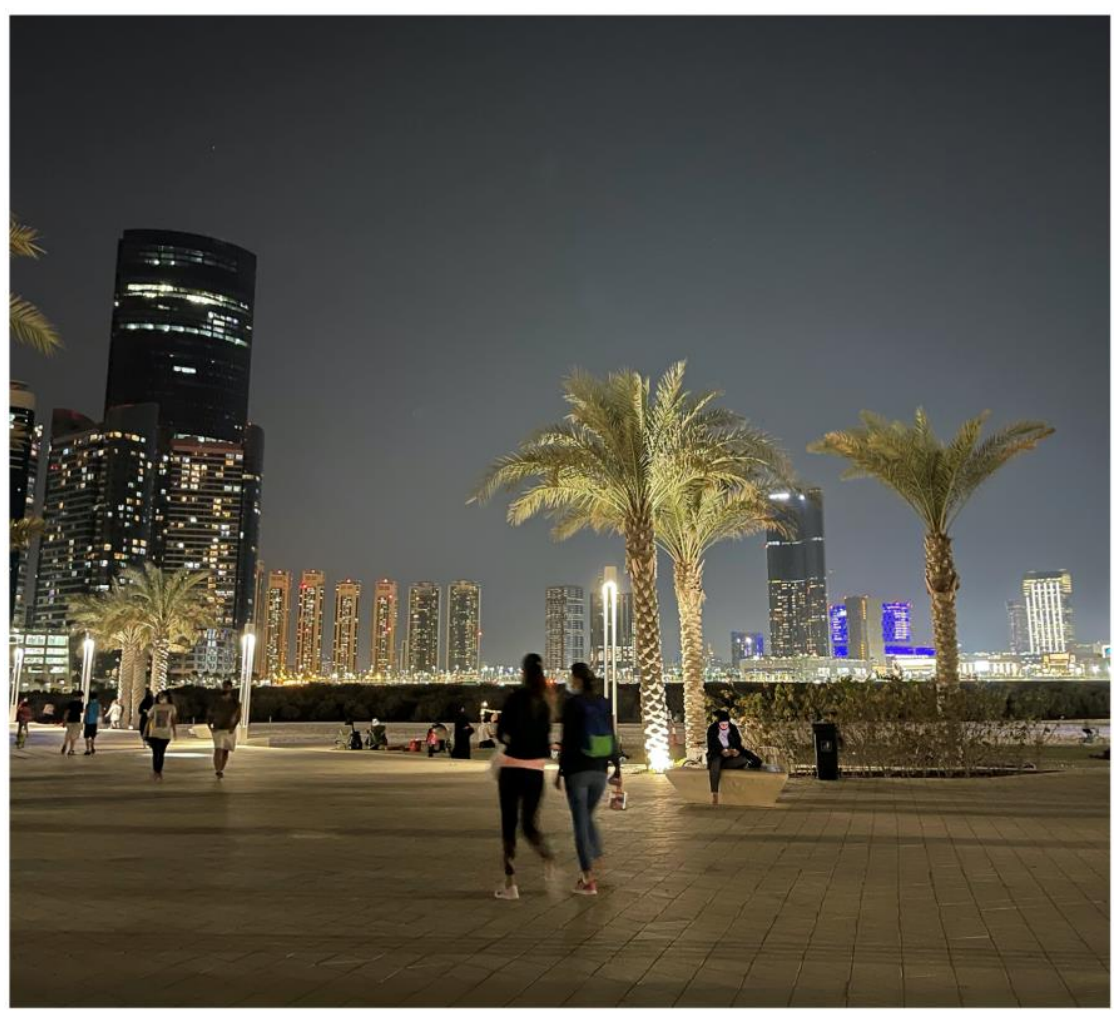

Figure 7 Adults active during the night
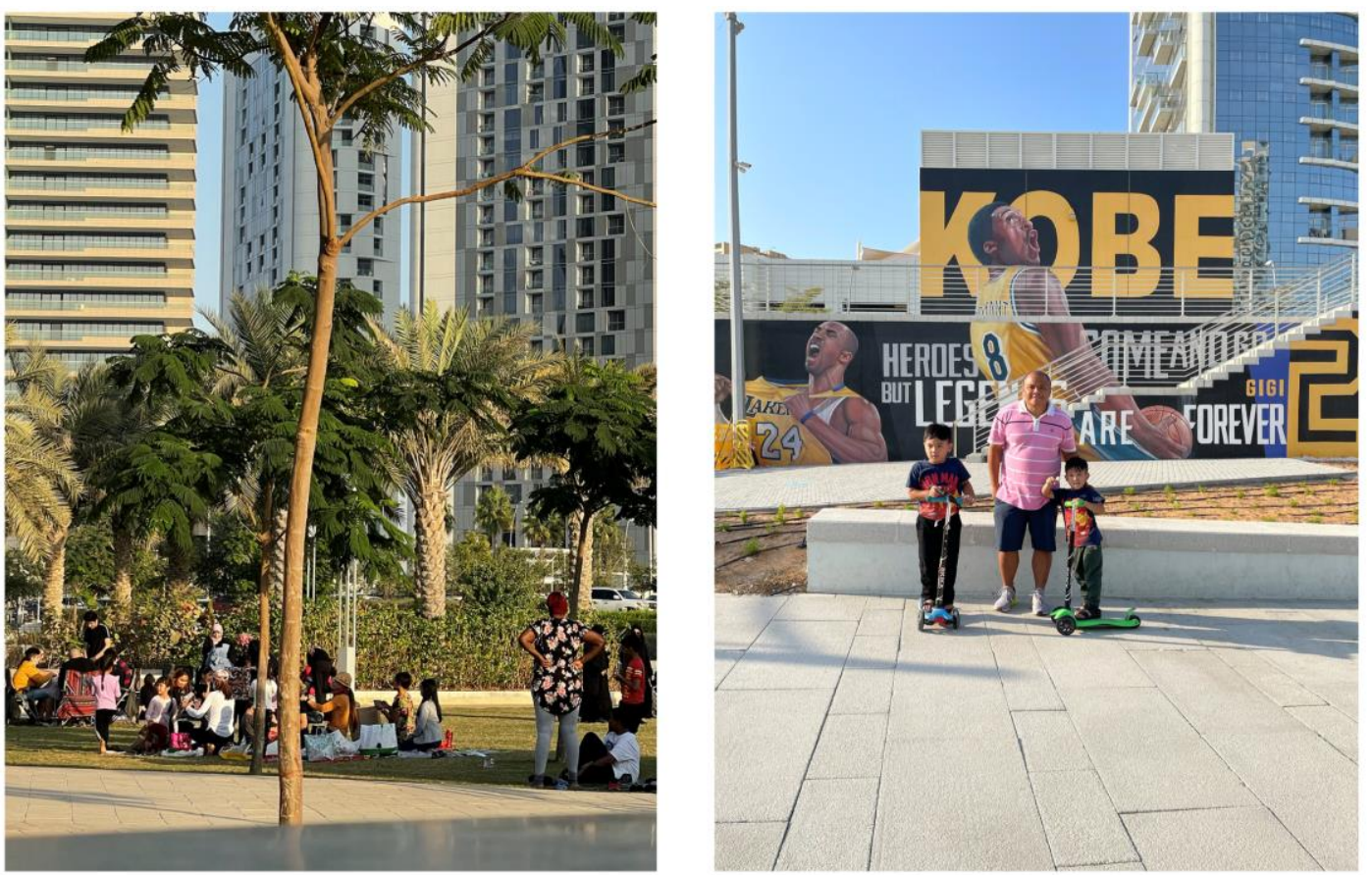

Figure 8 Filipino group of families

Another important discovery was the sighting of a big Asian group, which consisted of three families. When asked about covid and inclusion, they mentioned that they are sharing dwelling units with others, and sharing an open space is much easier. This was very interesting considering the fact that in the city, many families are living together in apartments and sharing the kitchen and bathrooms. Even with the COVID-19 restrictions in place the gap between their social boundaries was smaller compared to other groups who have come from nearby. 


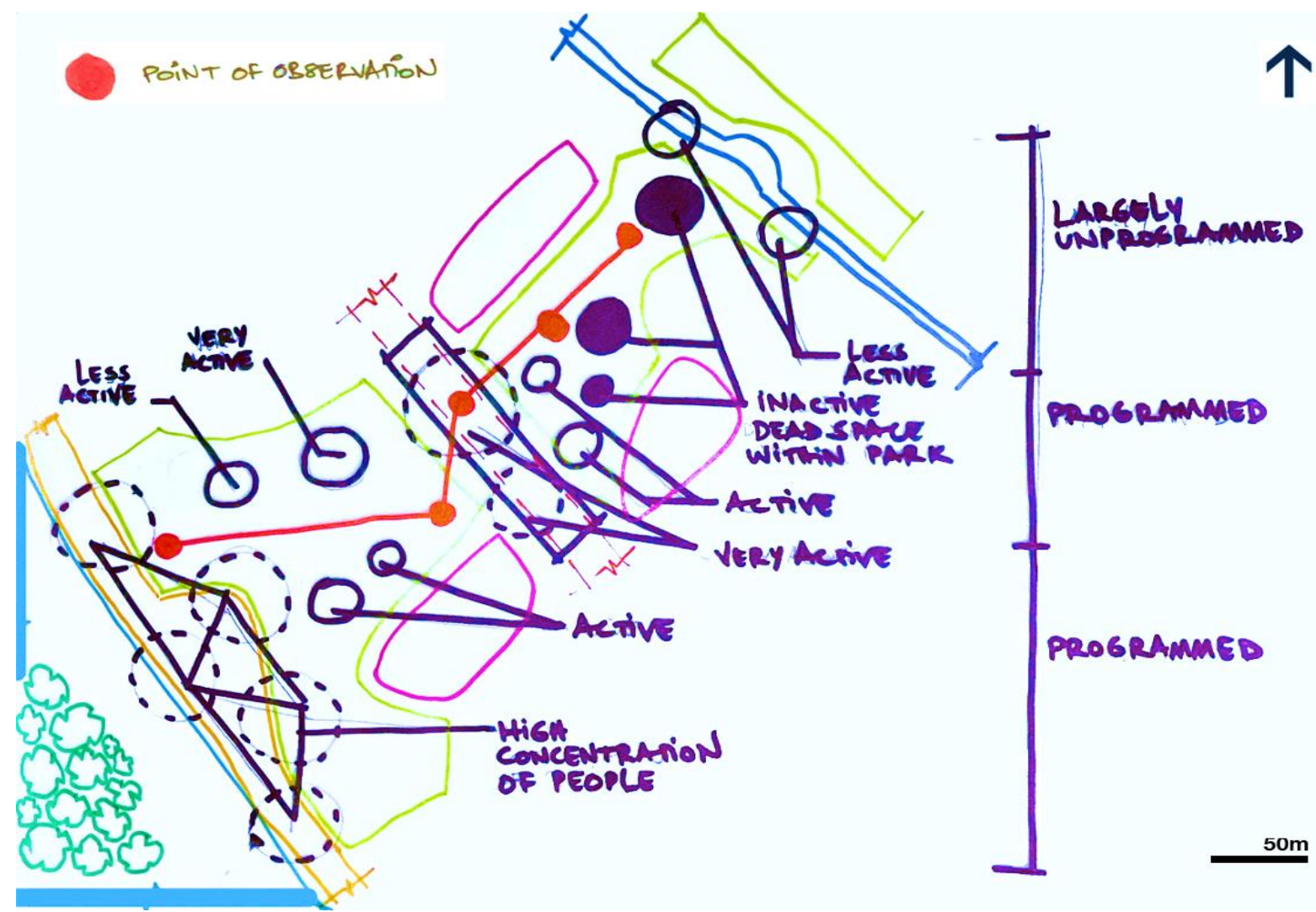

Figure 9 Activity Concentration Map - Reem Central Park
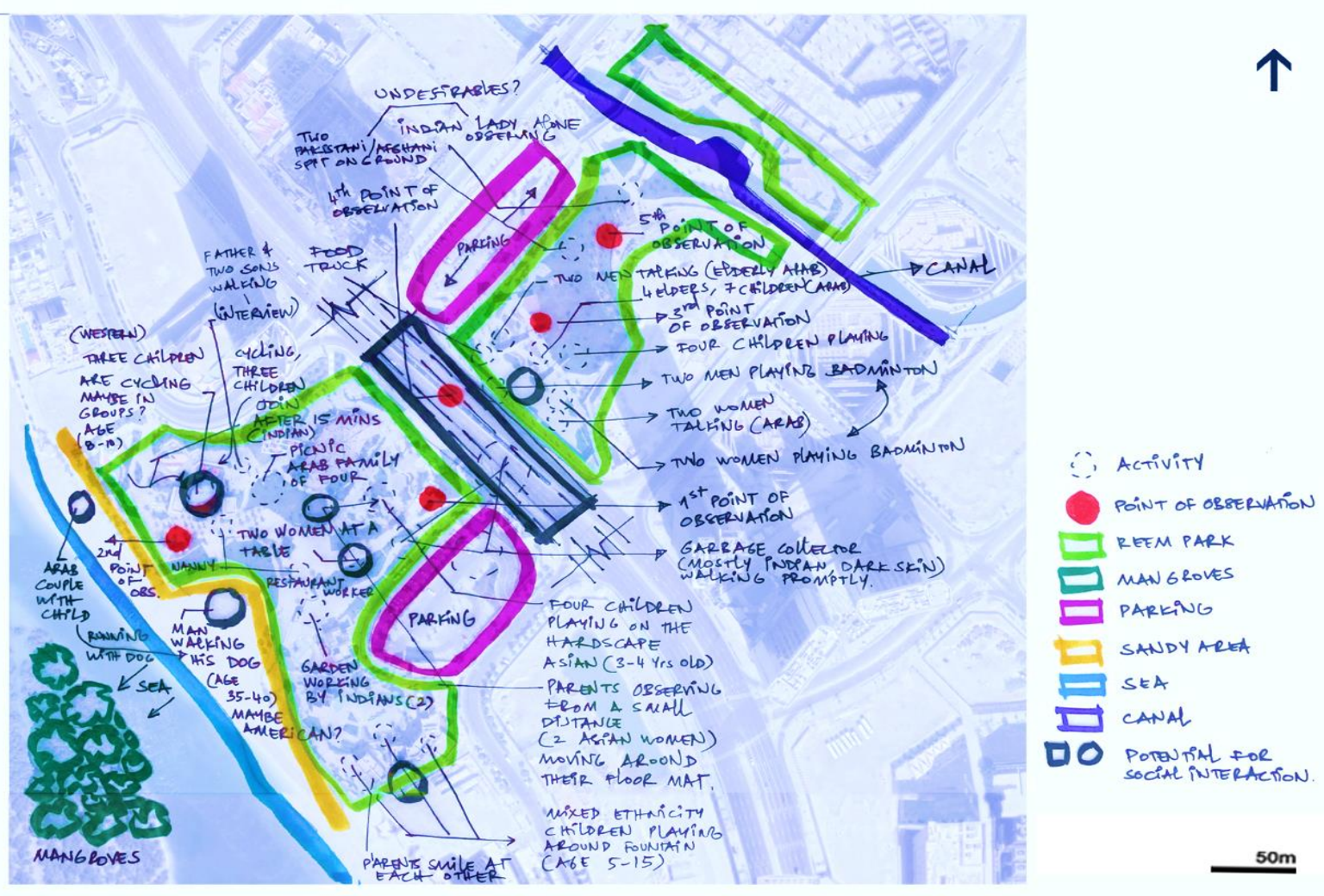

Figure 10 Typical Activity Overlay - Reem Central Park 


\subsection{Khalidya Park, Abu Dhabi}

The Khalidiya Park in Abu Dhabi is one of the oldest parks in Abu Dhabi city. Upon first glance, the park lacks all the modern amenities of newer parks, but creates a very free and relaxed atmosphere as it is like a breathing space within the city. Surrounding the park are mixed use establishments that have existed for around fifty years, and instills a calm quality around the busy and fast-moving cityscape. Located within the park is a large supermarket, where families and individuals nearby can come to buy groceries. Khalidiya is a busy neighborhood, and is a defining factor because al-though multi culturalism exists in both these scenarios, inter culturalism is more prominent in Khalidiya. Also, very close by is the Sheikha Fatima pint Mubarak Park, which used to be the Khalidiya Park for Ladies. It has been redeveloped with more modern amenities. Residential occupancy in this area is strongly of mixed ethnicity, based on observations and asking around in supermarkets. There are many trees in this park, and a lot of birds can be observed during various times of the day. Even during strong summer days, the trees provide ample shade and cooling. The only hardscape element is the walking/jogging track within and along the periphery of the park.

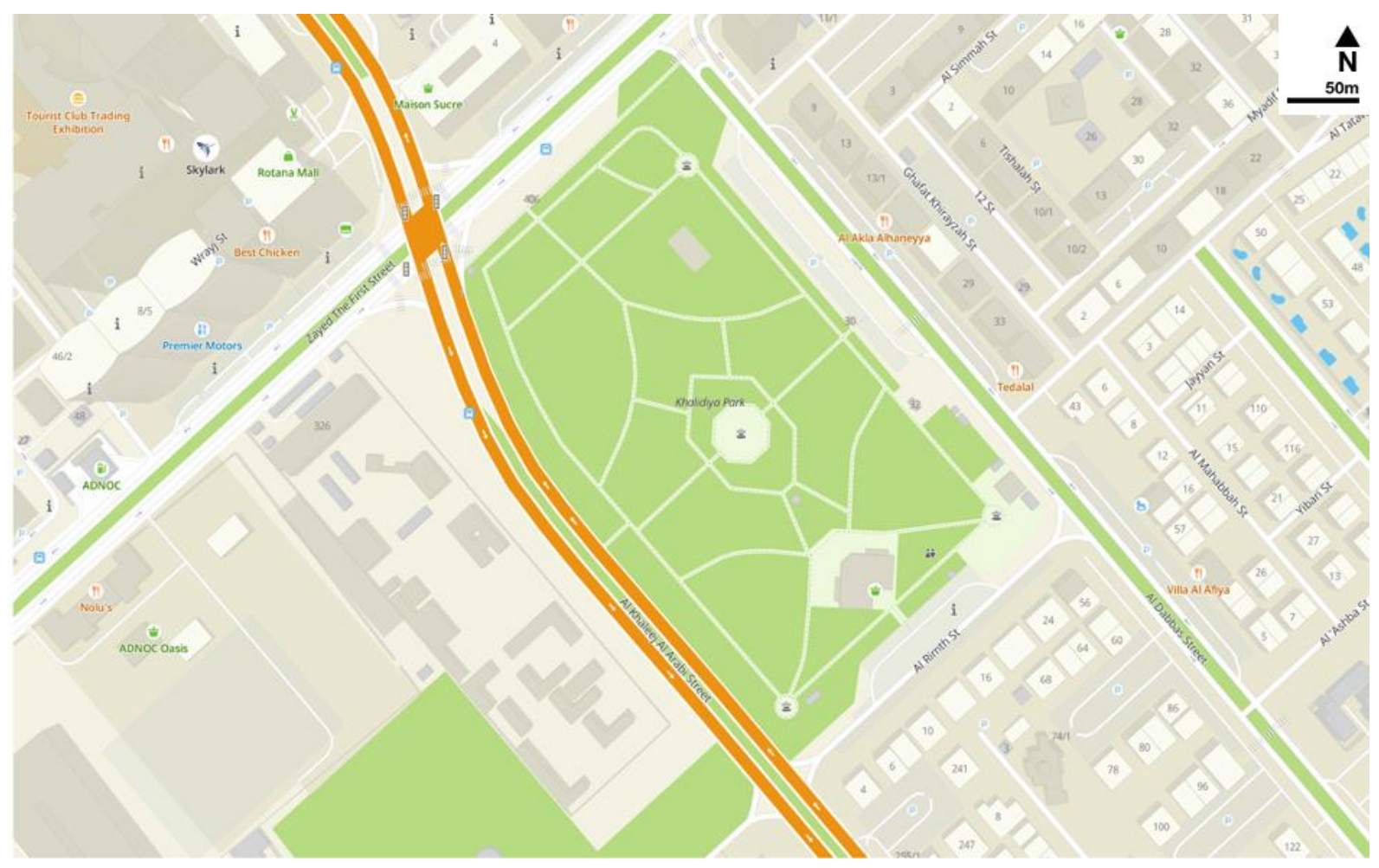

Figure 11 Khalidya Park

Unlike the wide range of activities offered in Reem Park, Khalidiya Park is more straightforward. We have a multipurpose court which can be used for football, basketball, etc. There is also a big children's play area, with swings and slides. The supermarket is at the southern end of the park, and in between, we have trees, footpaths for walking and jogging, and big lawns with a fountain at the center. Furniture I very well laid out in the park, with a lot of shaded seating spaces. Also, natural shaded cover is very high, extending almost the entire span of the park with tree shade available every 10-15 meters away. This natural system is more inviting for user programmed activities as compared to planned spaces like in Reem Park. Humans are unpredictable, after all, and a sense of freedom makes sure occupancy is always high.

The Park remains mostly empty during the day time; we can only see slight crowd coming in after noon, although the supermarket within the park serves shoppers. Even on weekdays, we can see the supermarket filled with at least $40-50$ people on average and these people directly come from the south 
east entrance. They also leave from the same way, without taking a moment to enjoy the park. This could be due to their hectic schedules, but this is one instance where too much accessibility to the park has hindered the space inactive during the morning times. In the afternoon, by around $2 \mathrm{pm}-3 \mathrm{pm}$, we can slowly see the crowd emerging, especially in the early evenings at around $5 \mathrm{pm}$. People of different races and cultures come as groups or alone. Sitting down alone in parks is not unusual, but in the case of Khalidiya it is an active task rather than in Reem, where it was passive and intermittent. The spatial layout is defined by the type of users that are more involvement based as compared to being time based, where users interact in transit. The latent environment activities such as sitting under a tree are supplementary spaces that are not forced upon the user. In Khalidiya Park, apart from benches, there are the shaded seating areas, where people like to spend some quality alone time. Observing Pakistani/Afghani men who are sitting in the shaded area while using their phone, both users are temporarily present and these seating areas are like small nodes within the park. By following them they started to walk, rather than being seated.

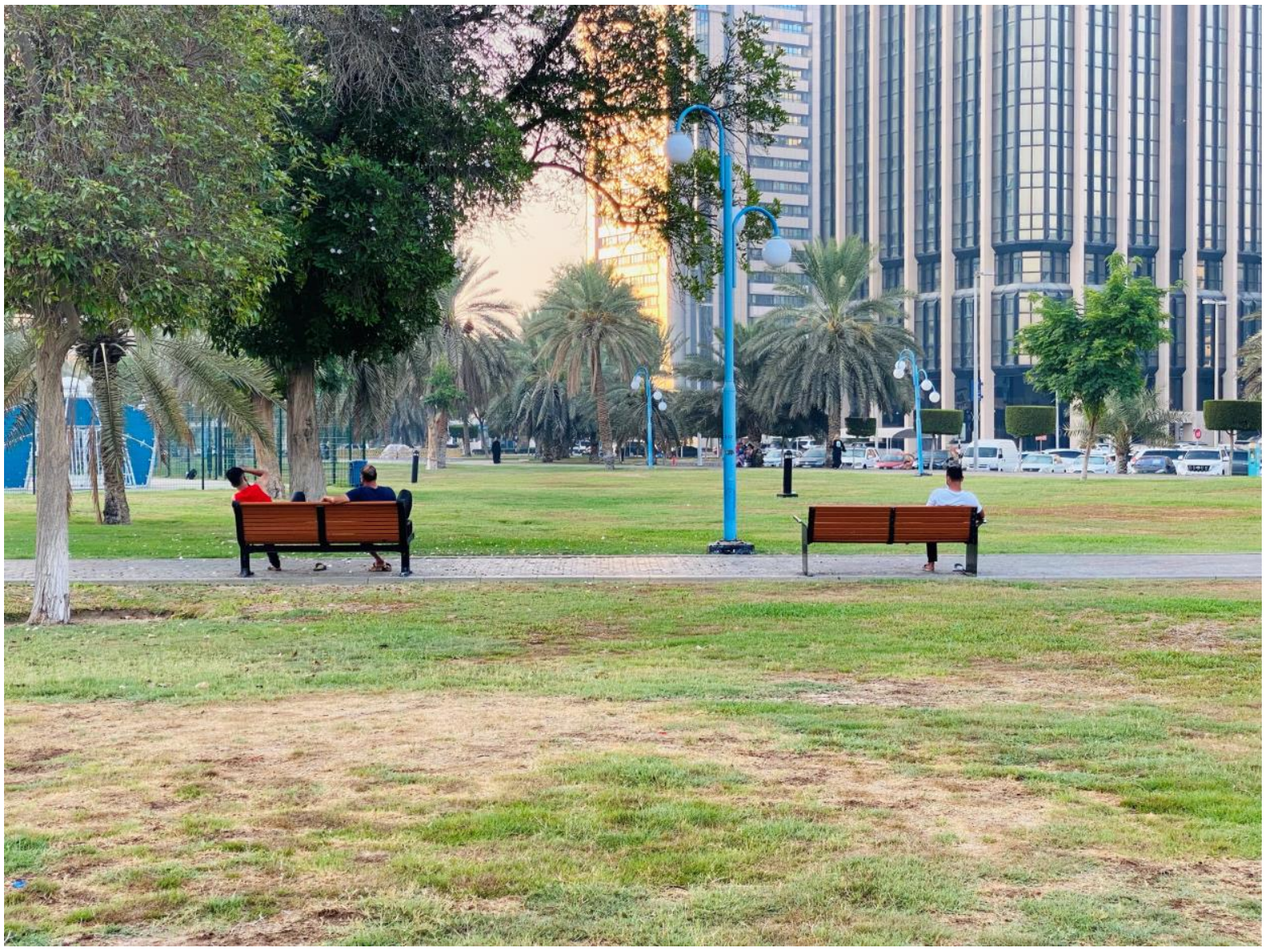

Figure 12 Usage of seating spaces

There is a trust between the user and the space which allows for co-habitation. Spatial occupation is in direct relation with the spatial capacity, which allows us to understand the behavioral patterns. By following them they started to walk, rather than being seated. Their nature from being temporarily present in the seating area changes to being continuously present within the confines of the park. In this example, we can understand these two individuals having a sense of community. Whereas in Reem Park they would be classified as undesirables, without a feeling of security. 


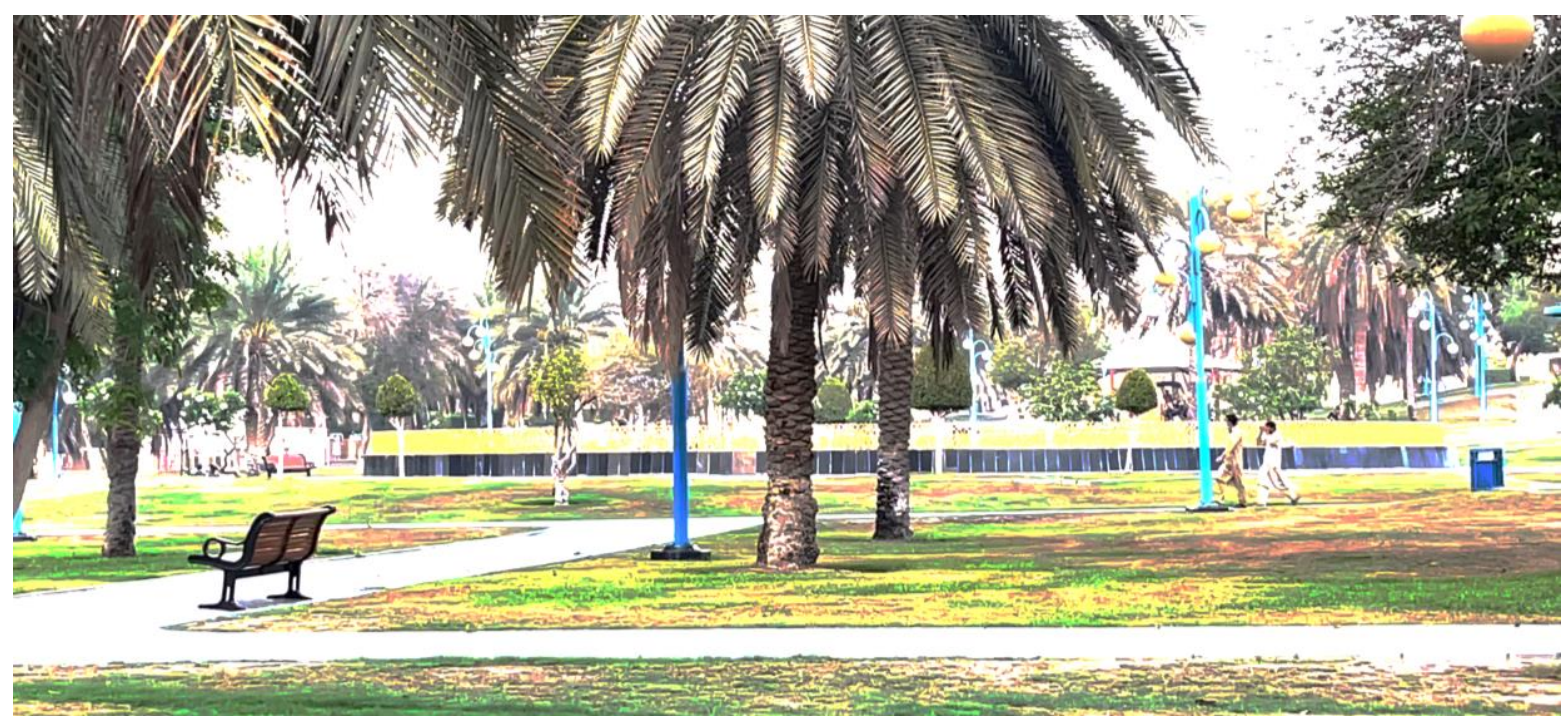

Figure 13 Afghani / Pakistani Men Walking

The same can be said in the case of an Indian couple that was interviewed. They told they prefer to be around people who come from the same part of the world. They also told that they stay in Musaffah, an industrial city in Abu Dhabi which is about 30 kilometers from the city. When asked about other parks, they told they come weekly to Khalidiya Park because it's a simple park which reminds them of parks in their home town. Many other people could be visiting here for the same reasons. The edges within the park in the form of hardscape and landscape dictate the interaction between various groups and individuals. Boundaries in the park, ironically dictate the boundaries of interaction here.

Just like in Reem Park, observation from different focal lengths has helped in perceiving the way people use the space, in relation to the scale of the park. Unlike Reem Park, due to the enclosed nature within the city, we can see the occupancy is high enough to a point where we get to see the same observation, regardless of the focal length. The Park is of human scale, which directly contrasts the monumental scale of the buildings surrounding it.

In the evenings, the park exhibits similar crowd and life. Again, when we compare it to Reem Central Park, Khalidiya is closely situated between buildings, and we there is very nice lighting due to the perceived scale of the buildings. Apart from lighting within the park, lights from these external buildings create a big impact due to the close proximity with the park. In the case of Reem Park, buildings are further away from the park and there is less of an impact when it comes to external lighting. Reem Park feels more isolated both within and outside the park.

The park exhibits a strong sense of life as the gap between people reduces because of the crowd. Territorial boundaries are less between groups, and external lighting at night has a very big role when it comes to perceived security and sense of community.

Its easier to capture the sense of transparency in Khalidiya. It was noticed that the users are continuously present within the park during usual activities such as cycling, walking, and jogging. Being in transit is intermittent within the park. On the other hand, when a seated man interacts with his children, the children here are in transit and are continuously present whereas the parent is stationary and temporarily present within the park. 


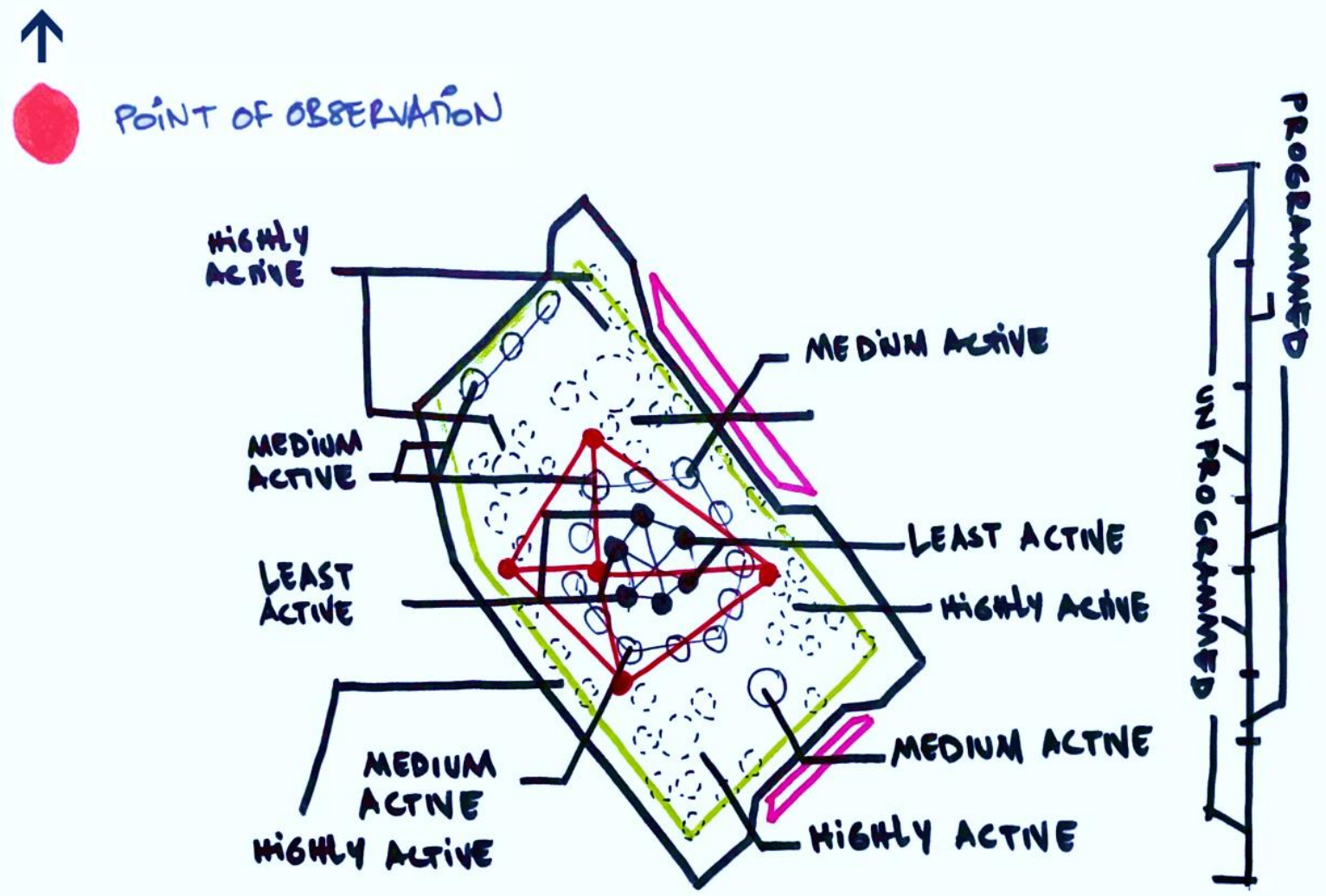

Figure 14 Activity Concentration Map - Khalidya Park

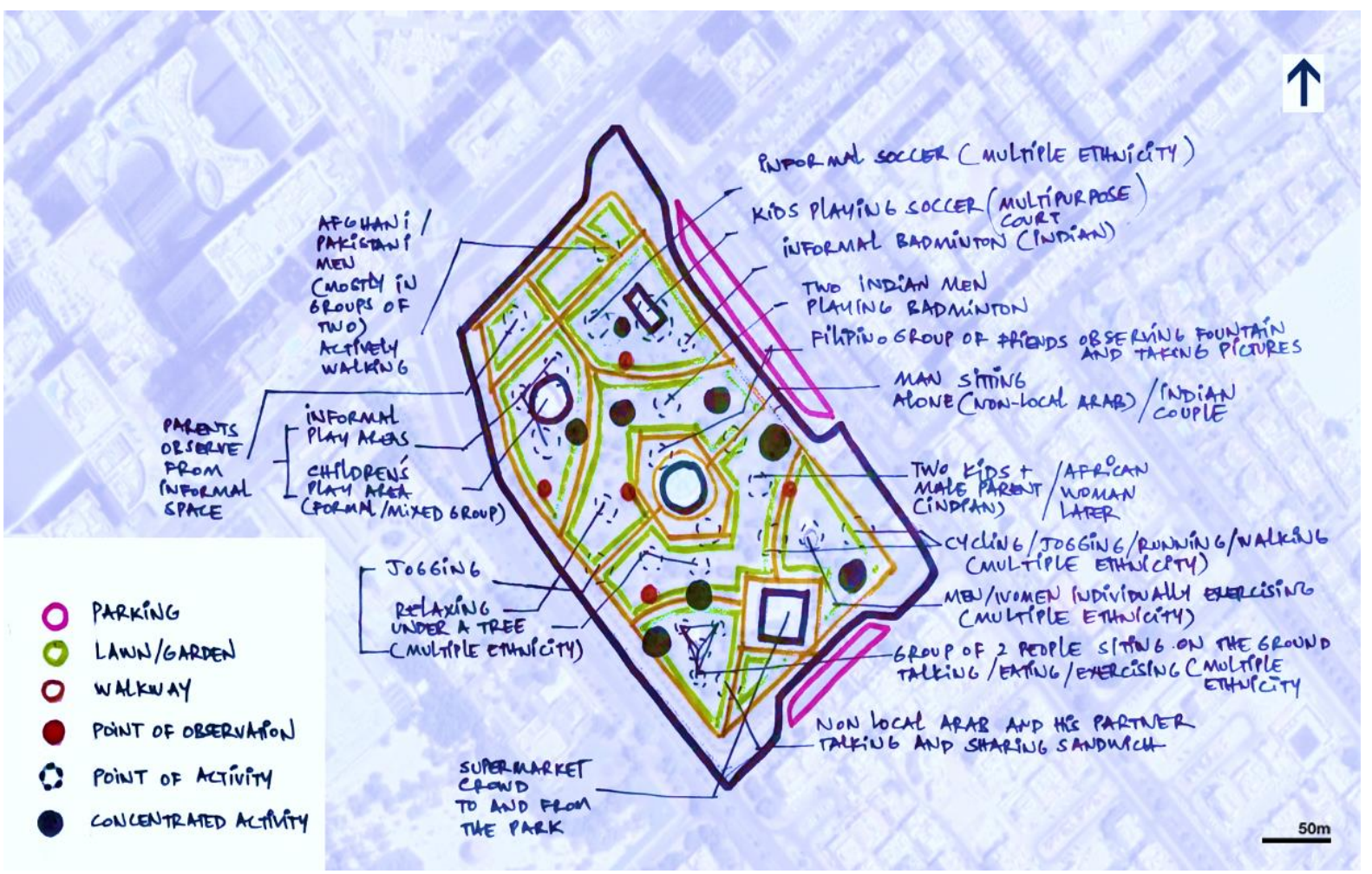

Figure 15 Typical Activity Overlay (Example) - Khalidiya Park 


\section{Guidelines and Recommendations}

\subsection{Primary Concept for Layout - Post Pandemic}

To improve adaptability, a hexagonal spatial layout could be used at for a comparable size of square, a hexagon has more nodes. For instance, in the current context of the pandemic, let's take four people who are standing two meters apart at four corners of a square. For six people, it would take lesser area in a park if they are standing at six corners of a hexagon. A grid in this pattern would spatially encourage in creating a habitat, which would link people more closely than that of a rectangular/square pattern.

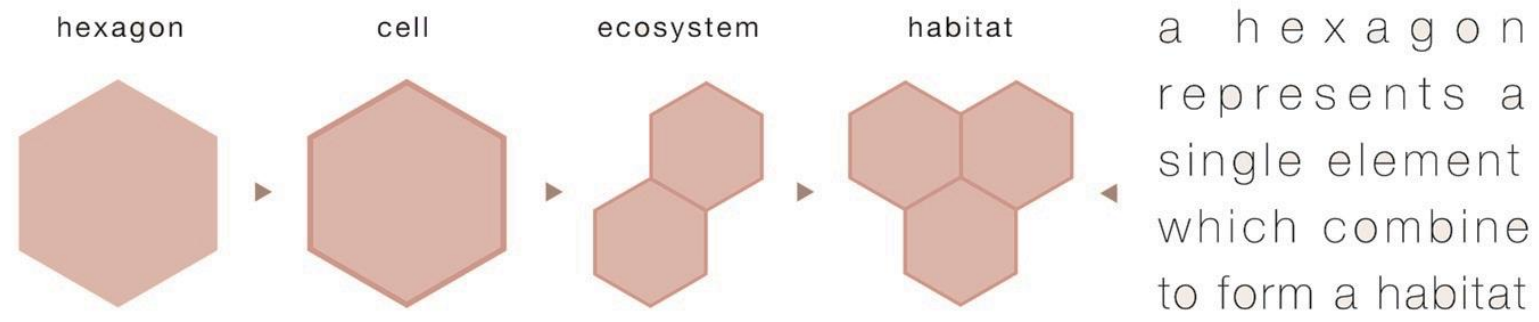

Figure 16 Shape of hexagon in imrpoving social inclusion

\subsection{Inclusive Clusters}

When designing a public space, activities must be in mutually inclusive zones rather than mutually exclusive zones. This reduces the gap between individuals and groups regardless of ethnic origins. The space also becomes more conducive, and this design can enable people to be more in transit, and reduce their boundary of space when not in transit.
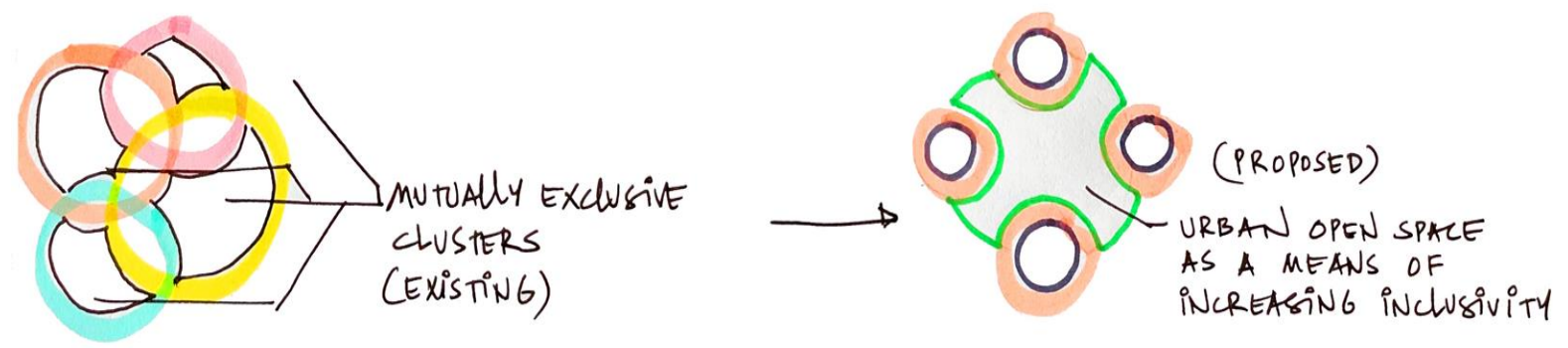

Figure 17 Mutually Exclusive vs. Mutually Inclusive Clusters

\subsection{Proximity and Reach}

However, to promote inter -culturalism, a good blend of both these strategies allowing for a growth of boundaries that is mutually inclusive while keeping the activity reach exclusive to those who want to take part in it. 


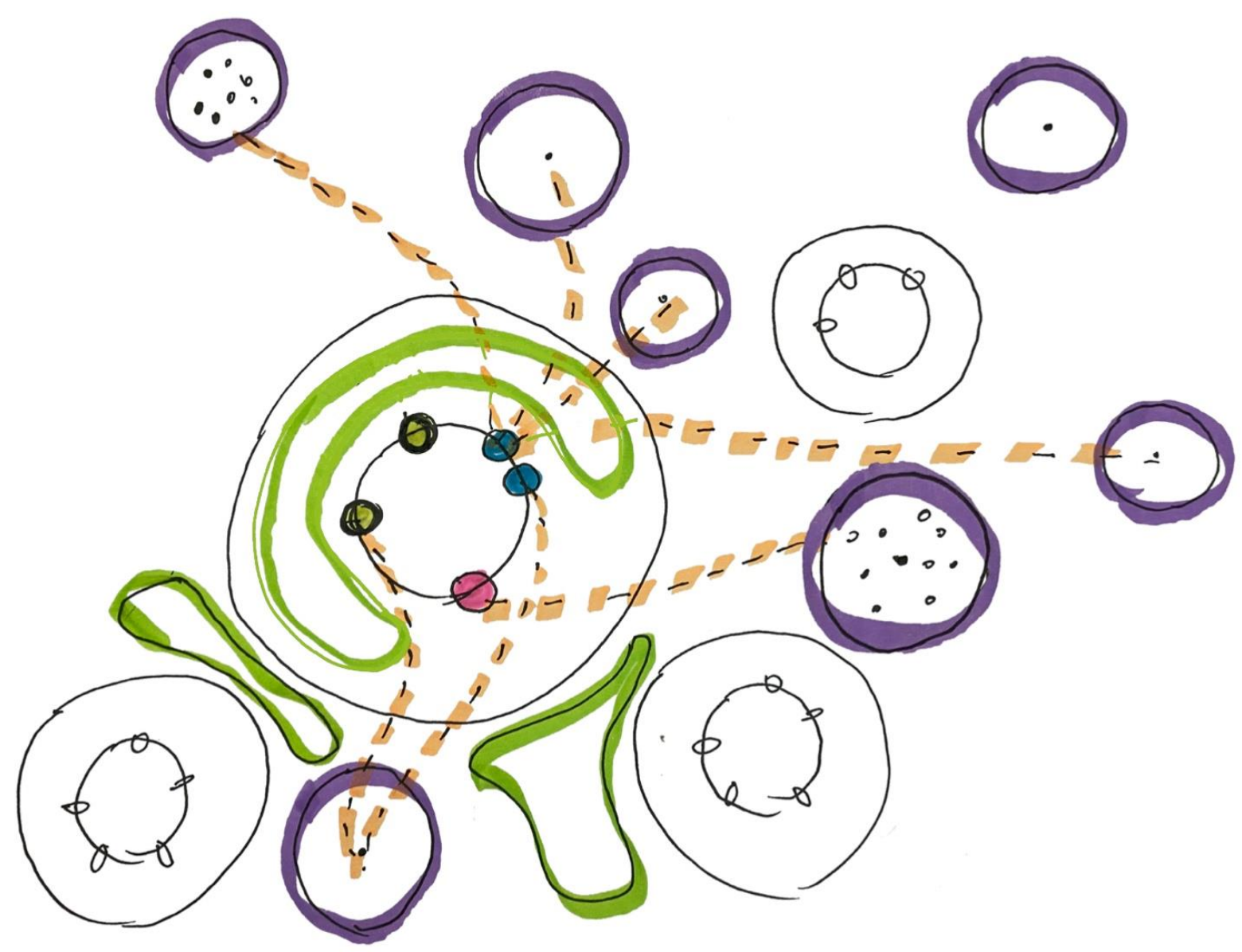

Figure 18 Mutually inclusive and exclusive Cluster

\subsection{Shared Space and Social Infrastructure}

Provision of facilities like equipment for working out, vending machines, kiosks, seating spaces, benches apart from activity cores should be provided. Provision of these facilities in a spatially distributed manner enables movement which is more inclusive in nature.
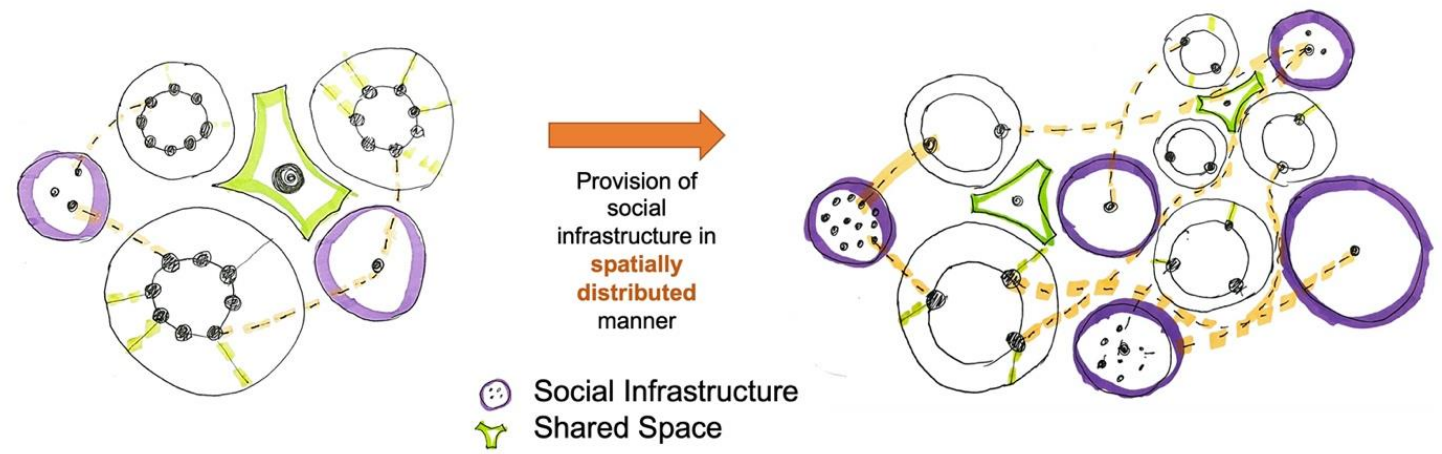

Figure 19 Spatial Distribution of Shared Social Infrastructure 


\subsection{Use of Information Boards}
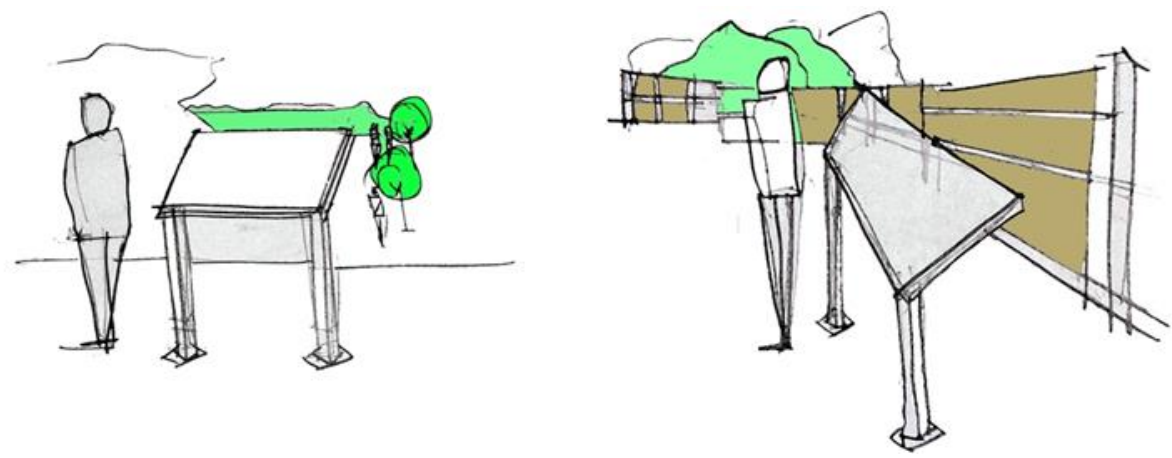

Figure 20 Information Boards draw people together

\subsection{Translucency and Permeability}

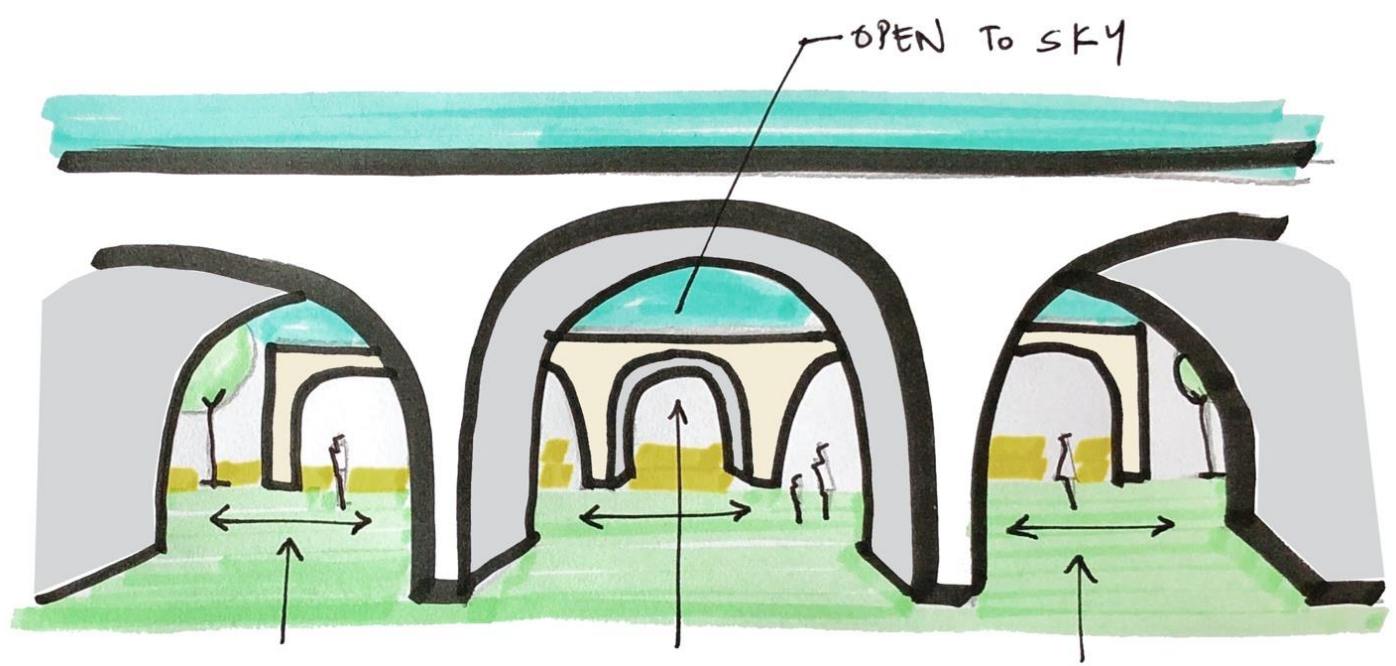

Figure 21 Permeable structures

\subsection{Land Marks and Nodes}

Landmarks and nodes can have multiple pause points where people can take a minute to breathe between their usual activities and do so by gathering together. A shaded membrane within a park, which can be like a green roof covering an interesting path or trail or a monumental node like a sculpture can attract people for taking photos, selfies and also the important act of asking strangers to take photos for themselves.
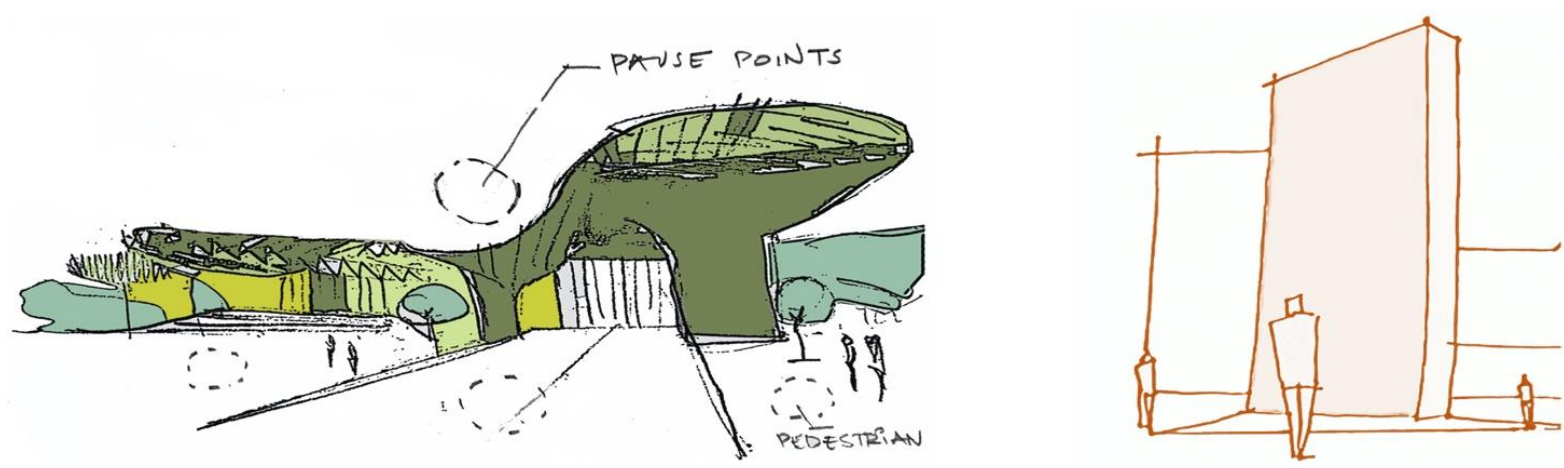

Figure 22 Pause Points 


\subsection{Benefits of Articulation}
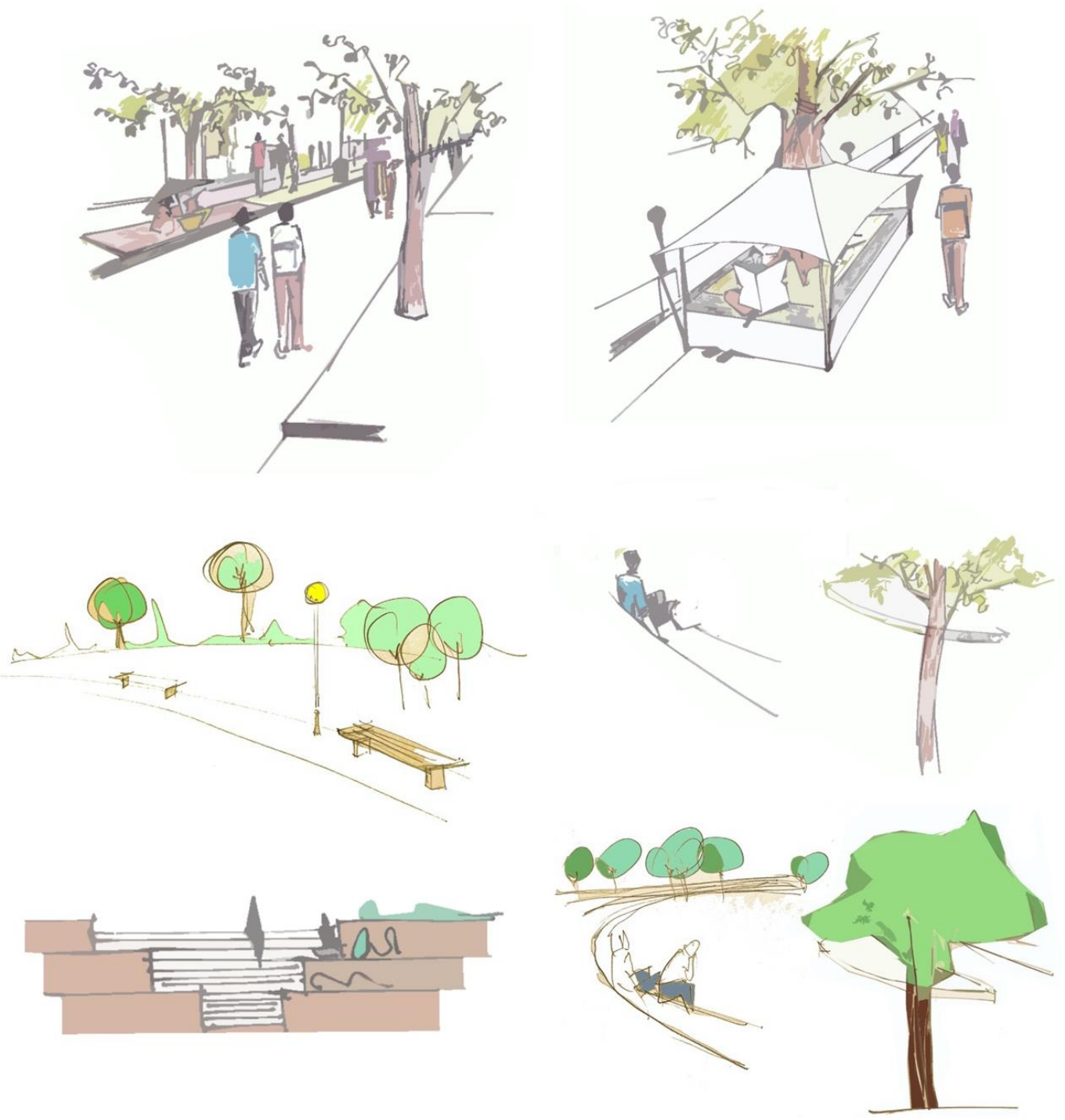

Figure 23 Horizontal and Vertical Articulation

Articulated spaces, whether vertical or horizontal can create depth and increase the perceived liveliness and sense of space within the same area.

\subsection{Proposed Application of Guidelines}

Based on the above guidelines, as an example, maps have been sketched to improve the levels of social inclusion within Reem Central Park and Khalidiya Park. This has been done based on the observations from the primary study while keeping in mind the aspirations and potential of the users and their spaces. 


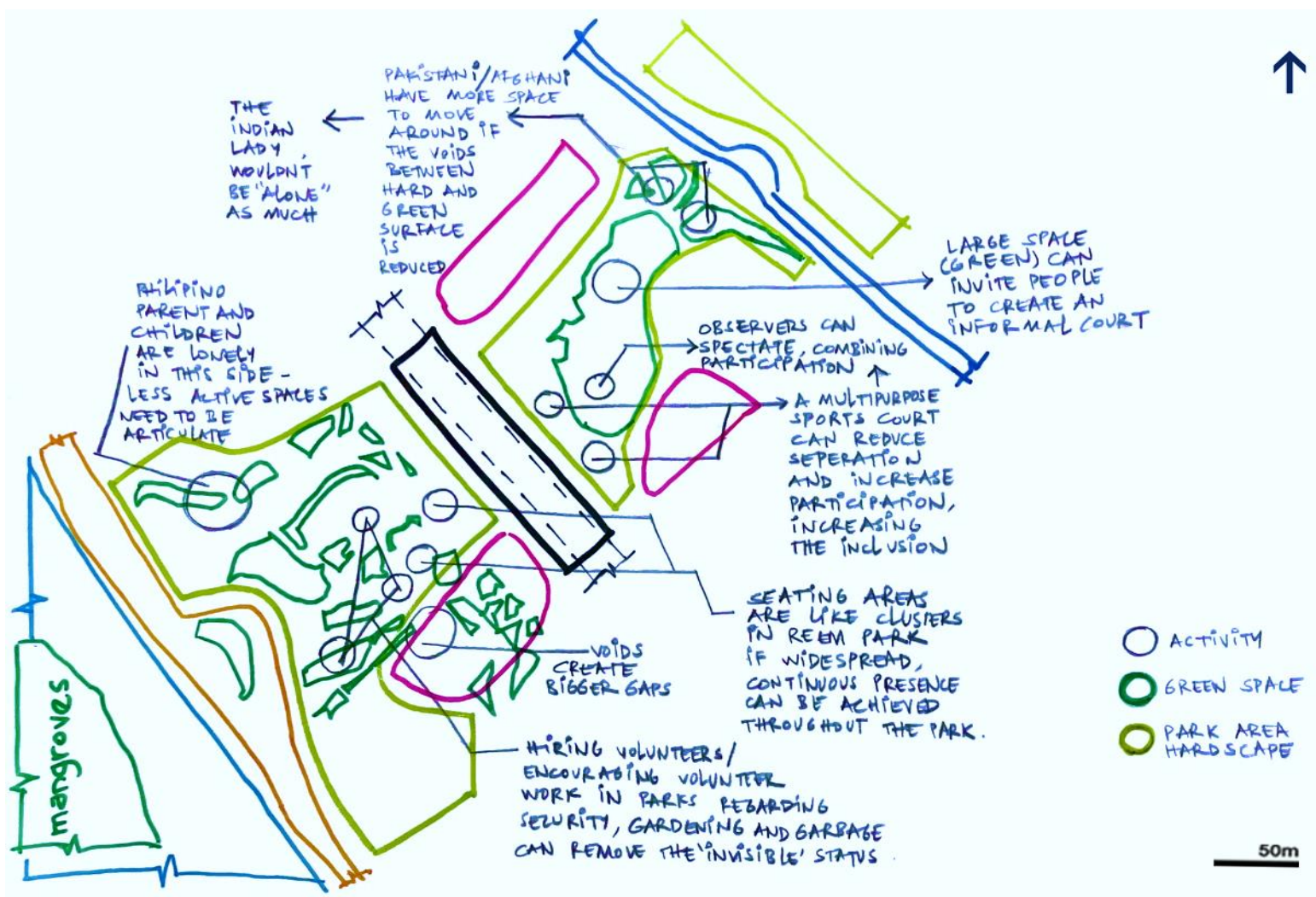

Figure 24 Aspirations and Potential Map - Reem Central Park

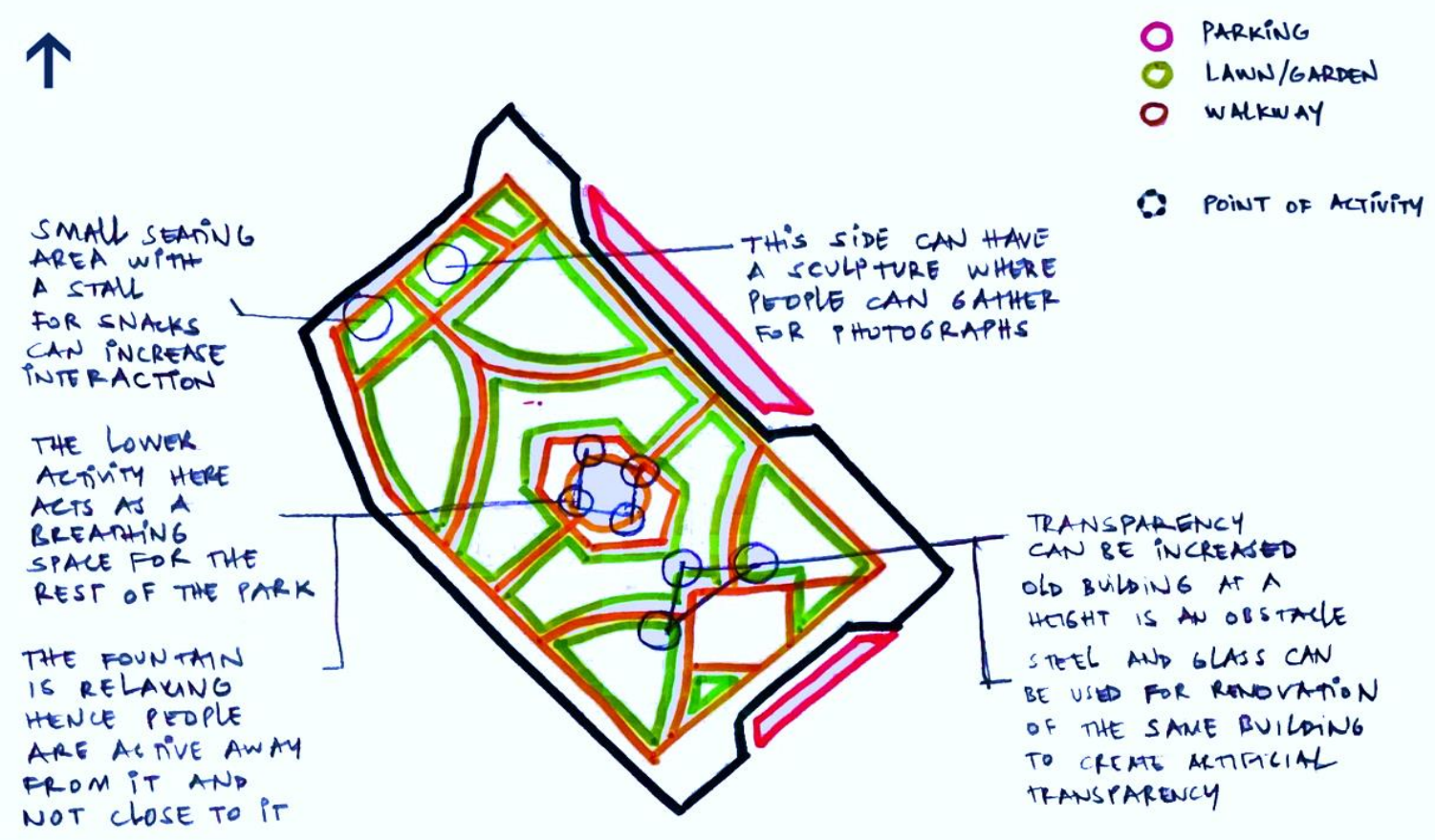

Figure 25 Aspirations and Potential Map - Khalidiya Park 


\section{Conclusion}

In the research, urban parks of Abu Dhabi were analyzed through photography on the basis of comprehensive literature review to find that how very small interventions like cutting the bushes / removing a fence from entry points of a park improved the accessibility and visibility of a park and further how this impacted the perspective of certain cultural groups. Even small factors like maintenance and presence of huge trees were seen to influence how people felt their cultural group was being treated. But it was also seen that certain events like birthdays and musical events bought people together irrespective of their backgrounds specially in vast open spaces.

Also, it was found that drawing on layers by hand is definitely more involving in sociological aspects, as compared to computer aided drawing and gave better descriptions about the aspirations of people.

This paper thus brings recommendations that can shape urban spaces as inclusive centers in a city. Further directions of this research will be to: update the typology of spaces at bigger scales in Abu Dhabi that can influence people and how cultural inclusiveness could be looked in-depth for each cultural type of community belonging to Abu Dhabi and see how the existing parks have to be re-planned in the near future as the diversity would increase in the capital of Abu Dhabi.

\section{References}

Alawadi, K. (2018) Lifescapes Beyond Bigness. Artifice Press. Available at: https://books.google.co.in/books?id=KcoJuAEACAAJ.

Amin, A. (2002) 'Ethnicity and the Multicultural City: Living with Diversity', Environment and Planning A: Economy and Space, 34(6), pp. 959-980. doi: 10.1068/a3537.

Burgess, J., Harrison, C. and Limb, M. (1988) 'People, Parks and the Urban Green: A Study of Popular Meanings and Values for Open Spaces in the City', Urban Studies, 25, pp. 455-473.

Byrne, D. and Goodall, H. (2013) 'PLACEMAKING AND TRANSNATIONALISM: RECENT MIGRANTS AND A NATIONAL PARK IN', 19(March), pp. 63-72.

Carr, S. et al. (1993) 'Public space', Public space, (October). doi: 10.4324/9781315794808-4.

Eyler, A. E. et al. (2002) 'Correlates of physical activity among women from diverse racial/ethnic groups', Journal of Women's Health and Gender-Based Medicine, 11(3), pp. 239-253. doi: 10.1089/152460902753668448.

Gobster, P. H. (2002) 'ManagingUrbanParksRaciallyEthnicallyDiverseClientele2002.pdf', Leisure Sciences, (February 2001), pp. Available 143-159. at: https://www.nrs.fs.fed.us/pubs/jrnl/2002/nc_2002_Gobster_002.pdf.

Greenhalgh, L. et al. (1995) Park life : urban parks and social renewal : a report. Stroud [England] : Comedia ; London : Demos.

Hutchison, R. (1994) 'Women and the elderly in Chicago's public parks', Leisure Sciences, 16(4), pp. 229-247. doi: 10.1080/01490409409513234.

Jacobs, A. and Appleyard, D. (1987) 'Toward an urban design manifesto', Journal of the American Planning Association, 53(1), pp. 112-120. doi: 10.1080/01944368708976642.

Johnson, C. Y. et al. (1997) 'Theoretical Perspective of Ethnicity and Outdoor Recreation: A Review of Synthesis of African-American and European-American Participation', General Technical Report SRS-11, pp. 1-17.

Kloek, M. E. et al. (2013) 'Crossing Borders: Review of Concepts and Approaches in Research on Greenspace, Immigration and Society in Northwest European Countries', Landscape Research, 38(1), pp. 117-140. doi: 10.1080/01426397.2012.690861.

Low, S. M. (1996) 'Spatializing Culture: The Social Production and Social Construction of Public Space in Costa Rica', American Ethnologist, 23(4), pp. 861-879. Available at: http://www.jstor.org/stable/646187. 
Low, S. M. (2002) 'Lessons from Imagining the World Trade Center Site: An Examination of Public Space and Culture', Anthropology \& Education Quarterly, 33(3), pp. 395-405. Available at: http://www.jstor.org/stable/3211099.

Mitchell, D. (2003) 'The Right to the City Social Justice and the Fight for Public Space by Don Mitchell (zlib.org).pdf', p. 140.

Özgüner, H. (2011) 'Cultural Differences in Attitudes towards Urban Parks and Green Spaces Cultural Differences in Attitudes towards Urban Parks and Green Spaces', (March 2013), pp. 37-41.

Rishbeth, C. (2004) 'Ethno-cultural representation in the urban landscape', Journal of Urban Design, 9(3), pp. 311-333. doi: 10.1080/1357480042000283878.

Rishbeth, C. and Powell, M. (2013) 'Place Attachment and Memory: Landscapes of Belonging as Experienced Post-migration', Landscape Research, 38(2), pp. 160-178. doi: 10.1080/01426397.2011.642344.

Sandercock, L. and Lyssiotis, P. (2003) 'Cosmopolis II : mongrel cities in the 21st century', in.

Sasidharan, V. (2000) 'Ethnicity and Urban Park Use: A Cross-Cultural Examination of Recreation Characteristics Among Six Population Subgroups', (619), pp. 10-16.

Setha Low, Dana Taplin, S. S. (no date) 'Rethinking Urban Parks: Public Space and Cultural Diversity'.

Trikalinou, L. (2015) 'Making Visible: The inhabitation of urban public space by irregular immigrants'. Available at: https://research.gold.ac.uk/11638/1/SOC_thesis_TrikalinouL_2015.pdf.

United Nations Deparment of Economic and Social Affairs (2016) 'Identifying social inclusion and exclusion, in Report on the World Social Situation 2016', Leaving no one behind, pp. 17-32. Available at: https://www.unilibrary.org/economic-and-social-development/report-on-the-world-social-situation-2016_5890648c-en. 